Pak. j. sci. ind. res. Ser. A: phys. sci. 2021 64A(2) 131-136

\title{
Empirical Support Design for Proposed Diversion Tunnels at Dasu Dam Site Pakistan
}

\author{
Muhammad Bilal $^{a^{*}}$ Muhammad Zaka Emad $^{b}$, Fawad UI Hassan a and Zaheer Ahmed \\ ${ }^{a}$ Department of Mining Engineering, Balochistan University of Information Technology Engineering and \\ Management Sciences, Quetta, Pakistan \\ ${ }^{b}$ Department of Mining Engineering, University of Engineering and Technology, Lahore, Pakistan
}

(received June 10, 2019; revised March 5, 2020; accepted March 6, 2020)

\begin{abstract}
This research work presents the rock mass characteristics and tunnel support system recommendations for hydroelectric power tunnels at Dasu dam site Pakistan. Two inverted U-shaped tunnels are proposed at the left bank of Indus river. The tunnels have inlet portals at an elevation of 773.00 $\mathrm{m}$ and outlet portals at an elevation of $758.00 \mathrm{~m}$. The thickness of rock cover above the tunnels is between 100 and $200 \mathrm{~m}$. Three types of rock are encountered at project site including Granulite, Amphibolite and Gabbronorite. Granulite rocks are encountered along the alignment of tunnels. Rock mass is classified using Rock mass rating (RMR) and Tunneling quality index (Q system). Support system is suggested based on values of $\mathrm{Q}$ and RMR. Correlation between Q-index and RMR is also derived.
\end{abstract}

Keywords: rock mass classification, RMR, Q-system

\section{Introduction}

Rock mass classification holds a vital role in selection of support system for a tunnel. In addition, it helps with estimating rock mass strength, and its deformability. Moreover, it indicates the degree to which rock can be ripped, dredged, excavated, cut and caved (Hashemi et al., 2010; Bieniawski, 1989). Numerous efforts have been made in crafting a superior classification scheme for rock masses, thus providing a basis for preliminary support design. Terzaghi was the first to develop a classification system. Since then, researchers have come up with numerous classification systems i.e. Rock mass rating, Rock structure rating, Rock quality designation, geological strength index etc. (Singh and Goel, 1999). Some of them are based on stand-up time, multiple parameter schemes etc. Most of the classification schemes work with multiple parameters including intact rock strengths, measure of intensity of fracturing, joint orientation and spacing, joint conditions, groundwater conditions, in-situ stresses, and geological structure (Bieniawski, 1993). Rock mass classification methods are either qualitative, for example GSI and Rock Load, or quantitative like, Q, RMR, etc. (Abbas and Konietzky, 2017). The most common rock mass classification schemes include the NATM (New Austrian Tunneling Method), Norwegian Method of Tunneling, RQD (Rock

*Author for correspondence;

E-mail: bilalkhan4p@mail.com
Quality Designation), RSR (Rock Structure Rating), RMR (Rock Mass Rating) and Q (Rock Tunneling Quality Index) (COSAR, 2004). Inter-conversion relationships have also been developed by many researchers (Laderian and Abaspoor, 2011).

Rock mass classification is an empirical method which puts to use an array of geotechnical data providing a general description of the rock mass properties (Ajalloeian et al., 2012). The rock mass classification schemes are very simple in application. The general problem encountered with rock mass classification is data collection, application and selection of a suitable classification scheme. Without preliminary knowledge of rock masses behaviour, it is impossible to design tunnels. The rock mass classification can work with limited data to produce reliable design. This feature is very handy for initial project design when data available is limited. Classification system provides a cost effective and rapid method of conducting a preliminary analysis (Brook and Hutchinson, 2008, Moon et al., 2001). It is always recommended to use more than one classification schemes to address a particular problem.

RMR, also known as Geomechanics Classification (Bieniawski, 1989) and Q-Index (Barton et al., 1974) are the often-used methods for designing tunnels and are used in combination. Both are used to assess stability, Q gives no clue of support limit while RMR system 
calculates stand-up time. Q system, and RMR to a minor extent, calculates the ground support design in terms of liner thickness and rock-bolt spacing etc. (Abbas and Konietzky, 2017). Both RMR and Q-Systems follow similar system, with ratings on different log-scale. $\mathrm{Q}$ is the result of product of ratios of various rock mass parameters, while RMR is summation of these parameters. The rock mass properties depend on discontinuities present in rock mass and intact rock properties. It is very important to consider the discontinuity data for designing. The prevalent geological conditions need to be determined input data for empirical tunnel design. A comprehensive site investigation program will help make tunnel design more reliable and reduce uncertainties.

In the present work tunnel support design and standup time is computed through RMR and Q-system for inlet, middle and outlet sections of proposed hydroelectric power tunnels at Dasu Dam site.

\section{Materials and Methods}

Engineering geological investigations. Dasu hydropower project is in northern Pakistan near the Dasu town in Khyber Pakhtunkhwa as can be seen from Fig. 1. The project site is located $345 \mathrm{~km}$ away from Islamabad at an elevation of $841 \mathrm{~m}$.

Two (Inverted U-shaped, L=1,261m / 1,101m) hydroelectric power tunnels with $17 \mathrm{~m}$ span and $20 \mathrm{~m}$ height are proposed. The tunnels have inlet portals at an elevation of $773.00 \mathrm{~m}$ and outlet portals at an elevation of $758.00 \mathrm{~m}$. The thickness of over burden on the tunnels is between 100 and $200 \mathrm{~m}$.

Three types of rock are encountered at project site i.e. Granulite, Amphibolite and Gabbronorite. The granulite rocks in most outcrops are massive to blocky, strong to very strong and slightly weathered to fresh. The rocks have primary, homogenous, medium to crystalline igneous texture and locally show metamorphic foliation.

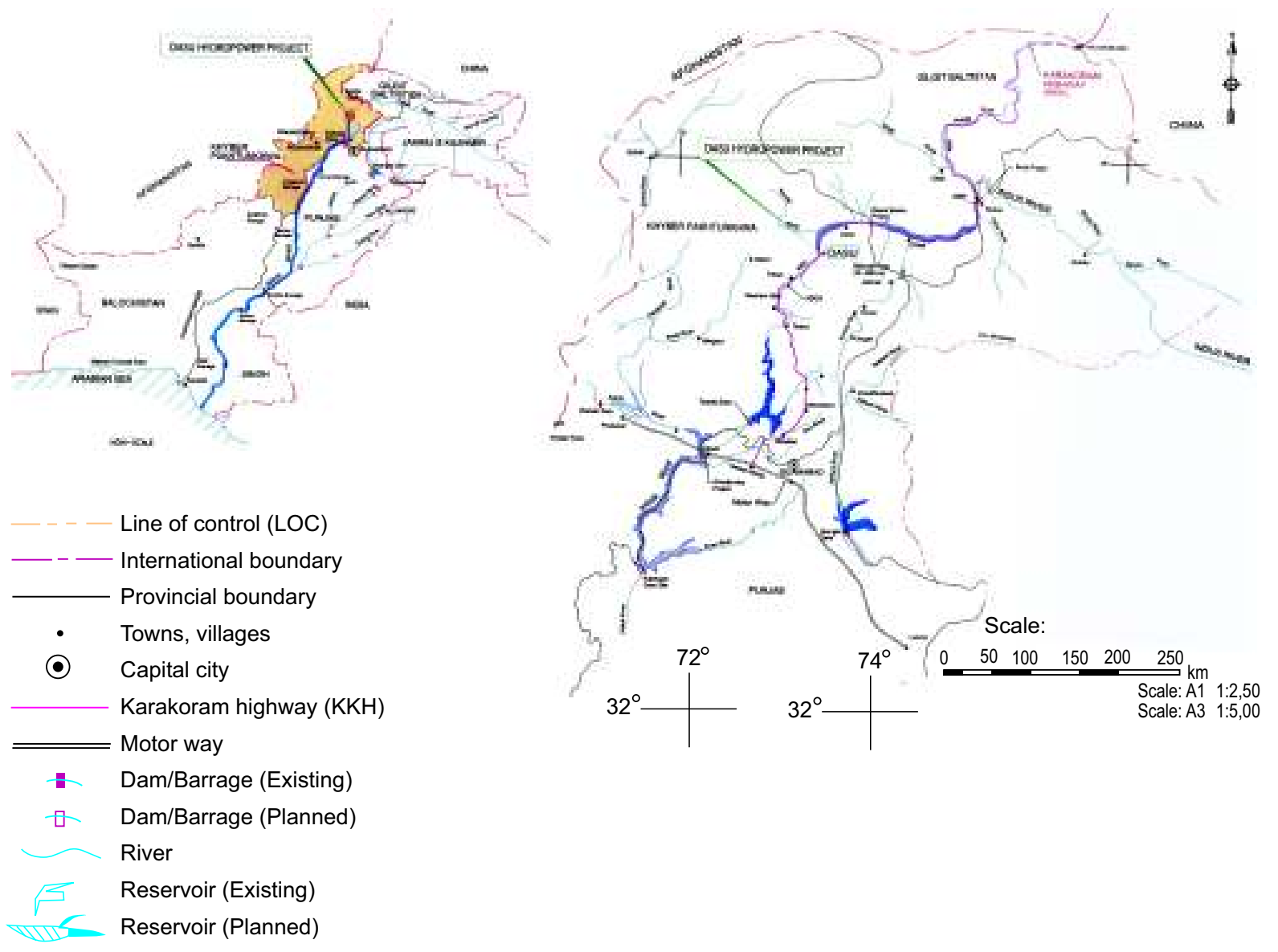

Fig. 1. Project location map. 
This rock type is moderately fractured, locally massive having 5 to 6 joint sets. The amphibolite is found in the downstream area of dam site. The amphibolite is lightmedium in color, having crystals size medium to coarse and moderately to strong foliation. Gabbronorite are light-dark grey, they are slightly weathered, and grain size is fine medium. Table 1 shows various mechnical and physical properties of these rocks determined in the Laboratory by ASTM method.
Three bore holes were drilled, each in the area of inlet (D5L-03), outlet (D5L-02) portal of tunnels and (D5P$01)$ at middle section. The location of all three boreholes is indicated in Fig. 2, along with the regional geology of the areas.

\section{Results and Discussion}

Two empirical methods RMR 89 and Q-system are used in combination for classification of rock mass under

Table 1. shows mechanical and physical properties of rocks determined in the laboratory as per ASTM standards.

\begin{tabular}{|c|c|c|c|c|c|c|c|c|c|}
\hline \multirow[t]{2}{*}{ Parameters } & \multicolumn{3}{|c|}{ Granulite } & \multicolumn{3}{|c|}{ Khoshe contact } & \multicolumn{3}{|c|}{ Amphibolite } \\
\hline & Max & Min & Mean & Max & Min & Mean & Max & Min & Mean \\
\hline Intact rock specific gravity & 3.25 & 2.61 & 2.95 & 3.35 & 2.88 & 3.03 & 3.40 & 2.73 & 2.97 \\
\hline Unit weight $\left(\mathrm{kN} / \mathrm{m}^{3}\right)$ & 33.7 & 25.5 & 29.2 & 33.2 & 27.9 & 30.1 & 31.8 & 27.2 & 29.1 \\
\hline Sonic velocity $(\mathrm{km} / \mathrm{s})$ & 6.13 & 3.10 & 4.55 & 5.97 & 3.88 & 4.78 & 5.79 & 3.30 & 4.55 \\
\hline Poisson's ratio & 0.41 & 0.02 & 0.15 & 0.39 & 0.03 & 0.17 & 0.54 & 0.01 & 0.11 \\
\hline Elastic modulus (GPa) & 69.7 & 5.2 & 39.7 & 64.8 & 16.3 & 36.9 & 93.3 & 12.1 & 37.8 \\
\hline Compressive strength (MPa) & 227 & 15 & 125 & 206 & 53 & 128 & 242 & 25 & 111 \\
\hline Tensile strength (MPa) & 18.1 & 3.6 & 11.3 & 22.1 & 3.6 & 9.9 & 22.1 & 3.6 & 9.9 \\
\hline
\end{tabular}

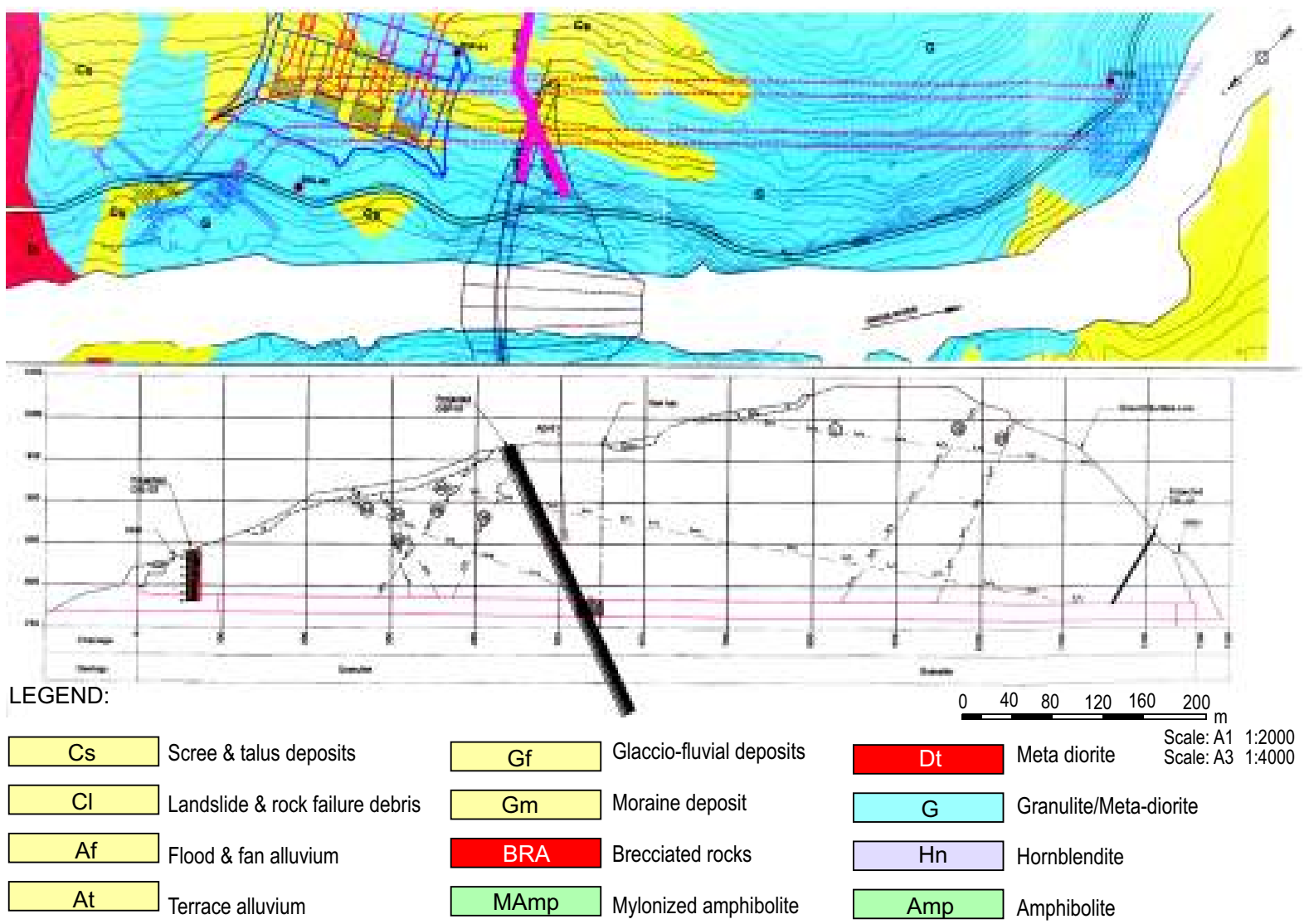

Fig. 2. Geological map along river tunnels. 


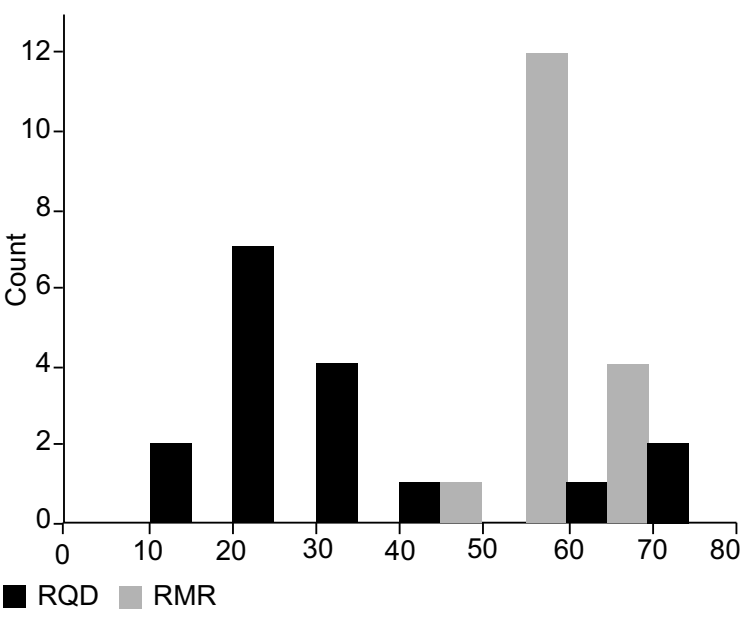

Fig. 3. Histogram of RQD and RMR for inlet section.

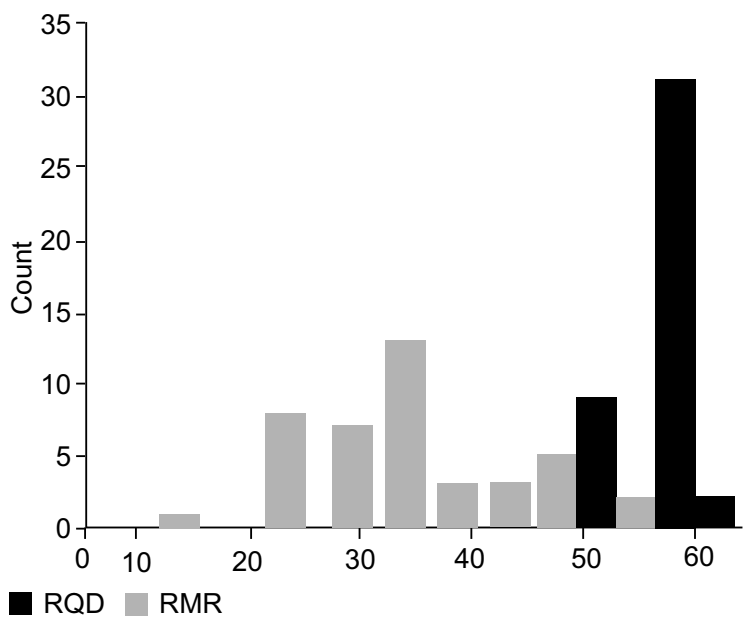

Fig. 4. Histogram of RQD and RMR for middle section.

discussion. For this purpose, three bore holes i.e. D5P01, D5L-02 and D5L-03 were used.

At inlet section the rock type is Granulite. Figure 1 and Table 2 shows that the value of RMR for this area changes from 51 to 58 . The mean RMR value is 54.5 , which shows that is fair. At middle section the dominant rock is Granulite again. The RMR value for this area changes between 51 and 61 as can be seen in Fig. 2 . The average value is 56 , which corresponds to fair quality rock. Similarly, at outlet section the major rock type is once again Granulite. Here the value of RMR fluctuated between 48 and 67 . The mean value is 57.5 and the rock mass is classified as a fair rock.

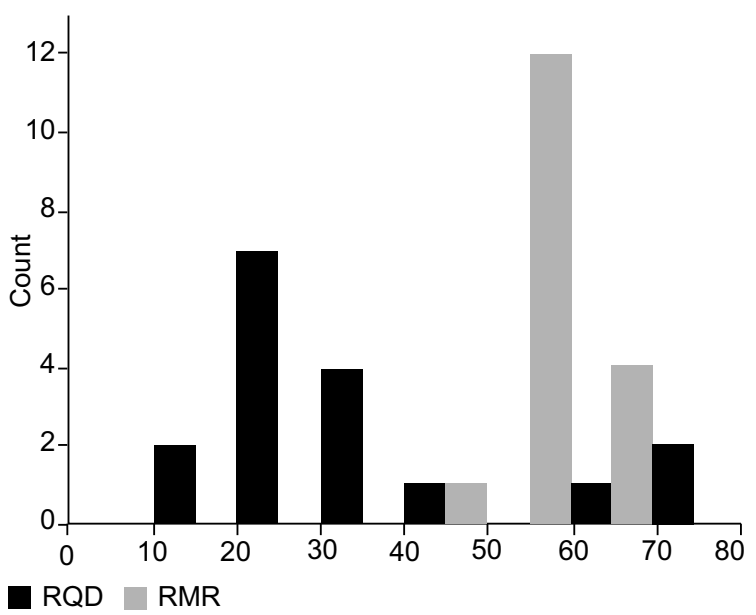

Fig. 5. Histogram of RQD and RMR for outlet section.

From Fig. 3-5, it can be noted from the values of RMR corresponding to respective RQD, that RMR values are showing rock quality as fair, while the RQD values show very poor and fragmented rock.

RQD is attributed to be "an index" showing quality of rock in problematic rock conditions with inherent weathering, fracturing, shearing, and jointing of a certain rock mass". RQD only considers the degree of jointing; giving the joint and discontinuity conditions no consideration (Deere, 1988).

Though the mean RQD value prevalent on the site is 25 which indicated towards a very jointed rock, but this deficiency is countered by the separation aperture, infilling, spacing of discontinuities and ground water conditions, designating the rock as fair.

Table 3 shows the values of Q-system and RMR calculated from borehole and laboratory testing data.

Correlation between Q-Index and RMR. Different equations were proposed previously by researchers (Laderian and Abaspoor, 2011). For the tunnels concerned, the empirical equation is $\mathrm{RMR}=6.67 \mathrm{ln} \mathrm{Q}$

Table 2. Values of Q and RMR for different sections of tunnels

\begin{tabular}{llll}
\hline \hline Sections & Rock type & Q-Index & RMR \\
\hline Inlet & Granulite & 1.9 & 54.5 \\
Middle & Granulite & 3 & 55 \\
Outlet & Granulite & 3.2 & 56 \\
\hline \hline
\end{tabular}


Table 3. Recommendation of support systems for different sections of tunnels based on Q and RMR values

\begin{tabular}{|c|c|c|c|}
\hline Sections & RMR & Q & $\begin{array}{l}\text { Average } \\
\text { standup } \\
\text { time (RMR) }\end{array}$ \\
\hline Inlet section & $\begin{array}{l}\text { Bolts length } 4 \mathrm{~m} \text {, Spacing b/w bolts } 1.5-2 \mathrm{~m} \\
\text { Shotcrete thickness } 5-10 \mathrm{~cm} \text { in crown, } \\
3 \mathrm{~cm} \text { in sides }\end{array}$ & $\begin{array}{l}\text { Fibre reinforced sprayed concrete thickness } \\
9-12 \mathrm{~cm} \text {,length of bolt } 3-5 \mathrm{~m} \text { spacing } \\
\text { b/w bolts } 2.2-2.6 \mathrm{~m}\end{array}$ & 1 week \\
\hline Middle section & $\begin{array}{l}\text { Bolts length } 4 \mathrm{~m} \text {, Spacing b/w bolts } 1.5-2 \mathrm{~m} \text {. } \\
\text { Shotcrete thickness } 5-10 \mathrm{~cm} \text { in crown, } \\
3 \mathrm{~cm} \text { in sides }\end{array}$ & $\begin{array}{l}\text { Fibre reinforced sprayed concrete thickness } \\
9-12 \mathrm{~cm} \text {, length of bolt } 3-5 \mathrm{~m} \text { spacing } \\
\mathrm{b} / \mathrm{w} \text { bolts } 2.2-2.6 \mathrm{~m}\end{array}$ & 1 week \\
\hline Outlet section & $\begin{array}{l}\text { Bolts length } 4 \mathrm{~m} \text {, Spacing b/w bolts } 1.5-2 \mathrm{~m} \\
\text { Shotcrete thickness } 5-10 \mathrm{~cm} \text { in } \\
\text { crown, } 3 \mathrm{~cm} \text { in sides }\end{array}$ & $\begin{array}{l}\text { Fibre reinforced sprayed concrete thickness } \\
9-12 \mathrm{~cm} \text {, length of bolt } 3-5 \mathrm{~m} \text { spacing } \\
\text { b/w bolts } 2.2-2.6 \mathrm{~m}\end{array}$ & 1 week \\
\hline
\end{tabular}

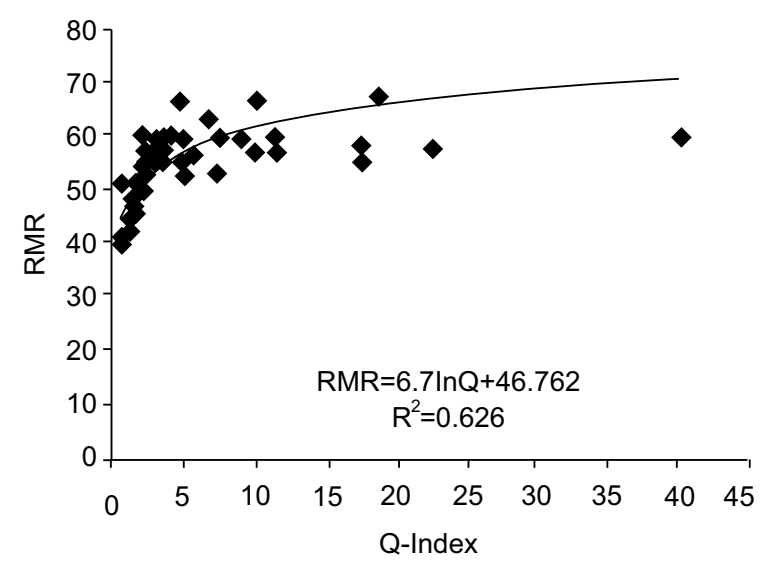

Fig. 6. Relationship between Q index and RMR.

+46.762 as shown in Fig. 6. Table 3 shows the proposed support system for different sections of diversion tunnels. This summarized support system is acquired from support system charts of Q-system and RMR based on the corresponding values. As it can be seen that for inlet section, RMR suggests $4 \mathrm{~m}$ length for rock bolts and spacing between rock bolts is $1.5-2 \mathrm{~m}$, while Q-system suggests $3-5 \mathrm{~m}$ length of rock bolts having space of 2.2$2.6 \mathrm{~m}$. Moreover, RMR suggests shotcrete's thickness $5-10 \mathrm{~mm}$ in crown and $3 \mathrm{~mm}$ in walls, while Q-system suggests fibre reinforced concrete.

To keep the safety factor in consideration, to counter the safety problems posed by the high degree of jointing, it is better to suggest over-support, unlike the support suggested by RMR.

\section{Conclusion}

Along the alignment of tunnels rock masses are characterized on basis of classification systems based on laboratory test results, bore holes data and field observations. Rock mass was classified based on RMR and Q-system for the inlet section, middle section and outlet section of tunnels. Support systems were suggested based on the results of RMR and Q index. In addition, more support is recommended due to poor RQD. The proposed support system may be verified by numerical modelling in order to check the interaction between rock mass and support system.

Conflict of Interest. The authors declare no conflict of interest.

\section{References}

Abbas, S.M., Konietzky, H. 2017. Rock Mass Classification Systems. In: Introduction to Geomechanics, pp. 1-48, $9^{\text {th }}$ edition, Department of Rock Mechanics, Technical University Freiberg, Germany.

Ajalloeian, R., Soofi, A., Salavati, M. 2012. Engineering geological assessment of diversion tunnel of Bakhtiari damsite (biggest two-arch concrete dam in southern Iran). Journal of Geological Research, 1-8.

Barton, N., Lien, R., Lunde, J. 1974. Engineering classification of rock masses for the design of tunnel support. Rock Mechanics, 6: 189-236.

Bieniawski, Z. 1993. Classification of rock masses for engineering: the RMR system and future trends. Comprehensive Rock Engineering, 3: 553-573.

Bieniawski, Z.T. 1989. Engineering Rock Mass Classifications: A Complete Manual for Engineers and Geologists in Mining, Civil, and Petroleum Engineering, 29-30 pp. John Wiley \& Sons, New York, USA. 
Brook, M.S., Hutchinson, E. 2008. Application of rock mass classification techniques to weak rock masses: A case study from the Ruahine range, north Island, New Zealand. Canadian Geotechnical Journal, 45: $800-811$.

Cosar, S. 2004. Application of Rock Mass Classification Systems for Future Support Design of the Dim Tunnel near Alanya. Master Thesis, 22 pp., Middle East Technical University, Ankara, Turkey.

Deere, D. 1988. The rock quality designation (RQD) index in practice. Rock Classification Systems for Engineering Purposes. In: Rock Classification Systems for Engineering Purposes, pp. 1-167, ASTM International.

Hashemi, M., Moghaddas, S., Ajalloeian, R. 2010.
Application of rock mass characterization for determining the mechanical properties of rock mass: a comparative study. Rock Mechanics and Rock Engineering, 43: 305-320.

Laderian, A., Abaspoor, M.A. 2011. The correlation between RMR and Q systems in parts of Iran. Tunnelling and Underground Space Technology, 27: 149-158.

Moon, V., Russell, G., Stewart, M. 2001. The value of rock mass classification systems for weak rock masses: a case example from Huntly, New Zealand. Engineering Geology, 61: 53-67.

Singh, B., Goel, R.K. 1999. Rock Mass Classification: A Practical Approach in Civil Engineering, pp. 12 Elsevier., Oxford, UK. 